\title{
A Note on the Nonlinear Effect in the Lorentz-Covariant Theory of Gravitation.
}

H. Fagundes and A. H. Zimerman

Instituto de F'́sica Teórica - São Paulo

(Lett. Nuovo Cimento, 3, 593 (1972))

In the right-hand side of eq. (13), p. 594, interchange the indices $\mu$ and $\nu$.

In the r.h.s. of eq. (17), p. 595, change the signs of the 4th through 9th of the twelve terms.

\footnotetext{
(C) by Società Italiana di Fisica
}

Proprietà letteraria riservata

Direttore responsabile: GIULIANO TORALDO DI FRANCIA

Stampato in Bologna dalla Tipografia Compositori coi tipi della Tipografia Monograf

Questo fascicolo è stato licenziato dai torchi il 22-X-1973 